\title{
Variation in reproductive life-history traits of birds in fragmented habitats: a review and meta-analysis
}

\author{
RENZO R. VARGAS, FRANCISCO E. FONTÚRBEL, ELISA BONACORSO \\ and JAVIER A. SIMONETTI
}

\section{Summary}

The effects of habitat fragmentation on the distribution and abundance of birds is a well-researched topic but there is little information published in terms of how habitat fragmentation affects reproductive life history traits. We reviewed the available literature on this subject and found that only $8 \%$ of the 1,433 studies dealing with birds in fragmented habitat studied life history traits and only $1.3 \%$ provided appropriate data to perform statistics. We found no effect of fragmentation on clutch and brood size patterns. Those patterns did not change when corrected by phylogeny. However, there is a significant heterogeneity among species responses, thus data on large-bodied, ground-nesting, and precocial birds suggest an increasing response in brood size in fragmented habitats. Finally, our review shows that despite birds being the most studied vertebrate group, crucial information such as the effects of habitat fragmentation on life history traits is still scarce and insufficient, especially on species of conservation concern. Indeed, only one out of 15 species reviewed here was threatened. Studies on reproductive, behavioural and life history trait variation are urgently needed in order to advance conservation actions.

\section{Introduction}

Habitat fragmentation is a major issue in conservation (Fahrig 2003). Reproductive success and survival of birds may vary with habitat fragmentation (Lampila et al. 2005). This variation in reproduction and survival may compromise the persistence of species in fragmented environments (Ewers and Didham 2006). There have been many studies of birds in fragmented habitats and most of these look at distribution and abundance of individual species. Thus, the subjects of 'birds', 'habitat modification' and 'fragmentation' are some of the most frequent topics in conservation publications (Clark and May 2002, Fazey et al. 2005). Therefore, it is expected that a sound empirical baseline would be available for assessing the consequences of habitat fragmentation upon the fitness of birds to inform conservation management.

Some of these studies have looked at which mechanisms make a species more susceptible to habitat fragmentation. These studies have associated variations in reproductive success and survival to life history traits of remaining species (Fahrig 2003, Ewers and Didham 2006). For example, habitat specialist, small-bodied, and ground-nesting birds tend to decrease or become locally extinct in habitat remnants (Lees and Peres 2008). Those changes in abundance and distribution in fragmented habitats are usually explained through species-specific sensitivity to habitat disturbance and are poorly understood (Ewers and Didham 2006). Nevertheless, the bulk of available information focuses on community and demographic change patterns, particularly on nest success as related to predation and parasitism (Batary and Baldi 2004, Lampila et al. 2005); while few studies have assessed patterns of life history changes in fragmented landscapes. 
Life history traits are not invariable and can change in a flexible way (Piersma and Drent 2003), or as local adaptations (Kawecki and Ebert 2004). Thus, life history variation may illustrate how phenotypic changes can help us to unravel the way in which organisms solve problems of time and energy allocation to reproduction, resulting from ecological demands related to habitat fragmentation (Ricklefs 1991).

Within this framework, this paper uses a meta-analysis of published studies to review the evidence as to whether life history traits change in response to habitat fragmentation. Understanding the magnitude and direction of change in birds' reproductive life history traits might inform conservation practices, pinpointing species whose life history attributes render them more extinction-prone in fragmented habitats, considering the phylogenetic context. Here, we analyse whether there is information to determine how clutch and brood size change, based on nest site, nest type, body size, trophic niche breadth and development type in birds dwelling in fragmented habitats.

\section{Methods}

We searched scientific publications in the ISI Web of Science database for 1988-2009 using a hierarchical criterion, first recovering articles dealing with habitat fragmentation or forest fragments. This suite of papers was later refined by the search term 'birds', and further refined by 'clutch size', 'brood size', 'number of broods', 'number of chicks', 'number of eggs', 'egg size', or 'nest attempt'. We only considered studies explicitly comparing life history traits in both fragmented and continuous habitats, excluding those that restricted their analysis to potential edge effects. Each paired fragmented-continuous comparison for the same species in a given habitat represented an independent case. Whenever there was more than one species in the same study, each of them was considered as an independent case.

To assess variation in life history traits, studies reporting mean, standard deviation or standard error, and sample sizes were analysed using Hedges' unbiased standardised mean difference as the metric of effect size (Rosenberg et al. 200o). Confidence intervals (CI) of effect sizes were estimated from the effect sizes and their variances, through bootstrap re-sampling procedures (using 999 permutations), for which we used a random effects categorical model (Rosenberg et al. 2000). Variation in clutch and brood size due to other life history traits was analysed in relation to body size (small $[11-22.5 \mathrm{~cm}]$ and large $[22.6-90 \mathrm{~cm}]$ ), nest type (open, closed), nest position (ground, elevated), diet breadth (generalist, specialist), and development type (altricial, precocial), whenever sample sizes were $\geq 5$. Heterogeneity of effect size was examined using the $Q$-statistics (Rosenberg et al. 2000). Publication bias was assessed through Kendall's Tau and Spearman rank correlation tests. These analyses were performed in the meta-analytic software MetaWin V.2.o ${ }^{\circledR}$ (Rosenberg et al. 2000).

To analyse these data in light of the evolutionary history of the species considered, we estimated a phylogenetic tree based on DNA sequences deposited in GenBank (http://www.ncbi.nlm.nih. gov/genbank/). We obtained a concatenated data matrix that included sequences of two nuclear genes: the recombination activating protein $I$ (RAGI) and the (non-coding) beta-fibrinogen intron 7. An initial phylogenetic tree contained representatives of all major taxonomic groups recognised in previous studies (Ericson et al. 2006, Hackett et al. 2008), as well as representatives of species considered in the meta-analyses. When sequences were not available for particular species, we included sequences of species in the closest taxonomic level (genus, family, or order). Even though relatively few species were considered in the meta-analyses, we included this broad taxonomic sample in the phylogenetic analysis to obtain a realistic alignment of sequences, and a good estimate of topology and branch-lengths. The data matrix for this analysis, including GenBank accession numbers for all sequences, is available upon request. Using the full dataset, we obtained maximum likelihood trees using GARLI (Zwickl 2006) Zwickl. After running to independent analyses, we selected the tree with the highest -ln likelihood score and ran 10o bootstraps replicates to assess nodal support at major clades. The best tree and the bootstraps proportions were inspected carefully 
to assure their general consistency with recent systematic studies (Ericson et al. 2006, Hackett et al. 2008). Finally, the best tree was pruned to retain only representatives of the species included in the meta-analyses.

Both conventional meta-analysis and phylogenetic meta-analysis were performed to assess the prevalence of fragmentation effects on bird life history trait change. For the phylogenetic metaanalysis, the phylogenetic covariance among taxa was taken into account and the phylogenetic cumulative effect size was determined following Adams (2008). The significance of the phylogenetic cumulative effect size was evaluated using a Student's t-test based on the standard error, as well as through randomization (Adams et al. 1997). Here, species' effect sizes and their associated weights were randomly assigned to tips of the phylogeny, and the phylogenetic cumulative effect size was recalculated. This procedure was iterated 9999 times, and the distribution of randomly generated cumulative effect sizes was used to evaluate the significance of the observed cumulative effect size. This analysis was performed in R (R Development Core Team 2006), based on the script used by Adams (2008).

\section{Results}

A total of 5,754 ISI articles were published on habitat fragmentation from 1988 to 2009. Almost $25 \%(1,433)$ of them were about birds. Nevertheless, only small fractions of these studies dealt directly with reproductive life history traits (clutch size $=3.3 \%$; brood size $=3.5 \%$; egg size $=3.1 \%$; nest attempts $=1.2 \%$ ). Moreover, only $1.3 \%$ (18) of these publications met our criteria, comprising 69 independent cases: 28 for clutch size (from 11 articles), 39 for brood size (from 1o articles) and two for nest attempts (from two articles); no article provided comparative information on egg size (Table 1). There were insufficient studies to attempt any analyses on the number of nest attempts. Eighteen studies reported only mean values with no information on sample size or variation around the mean, thus, precluding their inclusion in this analysis.

For the whole species dataset, neither clutch size nor brood size varied in fragments compared to continuous habitats $(d=-0.12,95 \% \mathrm{CI}=-0.36-0.11, \mathrm{n}=26$; and $d=-0.02,95 \% \mathrm{CI}=-0.16-0.13$, $n=23$, respectively). Nevertheless, a significant heterogeneity indicates that the variance among effect sizes is greater than expected by chance (Table 2). Although no significant effects were observed for clutch size due to other life history traits, large bodied, ground nesting, and precocial birds exhibited larger brood sizes in fragmented habitats (Table 2). No publication bias was detected for clutch size (Kendall's Tau $=-0.05, P=0.74$; Spearman $R_{\mathrm{s}}=-0.08, P=0.71$ ) or brood size (Kendall's Tau $=0.03, P=0.85 ;$ Spearman $R_{\mathrm{s}}=0.01, P=0.97$ ). Furthermore, using

Table 1 . Sample sizes representation for each of the reproductive life history traits evaluated in publications related to habitat fragmentation. Number of cases and species per family, recorded for clutch, brood, and nest attempt traits.

\begin{tabular}{|c|c|c|c|c|c|c|}
\hline Family & Cases & Species & Cases & Species & Cases & Species \\
\hline Climacteridae & $\mathrm{O}$ & $\mathrm{O}$ & 3 & 1 & 1 & 1 \\
\hline Muscicapidae & $\mathrm{O}$ & $\mathrm{O}$ & 2 & 2 & o & $\mathrm{O}$ \\
\hline Paridae & 20 & 2 & 15 & 2 & $\mathrm{O}$ & $\mathrm{O}$ \\
\hline Petroicidae & 1 & 1 & $\mathrm{O}$ & $\mathrm{O}$ & $\mathrm{O}$ & $\mathrm{O}$ \\
\hline Picidae & 2 & 1 & $\mathrm{O}$ & $\mathrm{O}$ & $\mathrm{O}$ & $\mathrm{O}$ \\
\hline Rhinocryptidae & 1 & 1 & $\mathrm{O}$ & $\mathrm{O}$ & $\mathrm{O}$ & $\mathrm{O}$ \\
\hline Sittidae & $\mathrm{O}$ & $\mathrm{O}$ & 1 & 1 & $\mathrm{O}$ & $\mathrm{O}$ \\
\hline
\end{tabular}


Table 2. Hedges' $d$ effects of different life history traits in relation to clutch and brood size. Sample sizes shows number of cases number of species analysed. Variables with sample size lower than 5 were not evaluated (N/E). ${ }^{*}=Q_{\text {between }}$ significant at $P<0.05$.

\begin{tabular}{|c|c|c|c|c|c|}
\hline \multirow[t]{2}{*}{ Trait } & \multirow[t]{2}{*}{ Level } & \multicolumn{2}{|l|}{ Clutch size } & \multicolumn{2}{|l|}{ Brood size } \\
\hline & & Sample size & Effect & Sample size & Effect \\
\hline \multirow[t]{2}{*}{ Body size } & Small & $23 / 5$ & Neutral & $18 / 5$ & Neutral \\
\hline & Large & $3 / 2$ & $\mathrm{~N} / \mathrm{E}$ & $5 / 2$ & Increase \\
\hline \multirow[t]{2}{*}{ Nest type } & Open & $22 / 4$ & Neutral $^{*}$ & $23 / 7$ & Neutral \\
\hline & Closed & $4 / 3$ & $\mathrm{~N} / \mathrm{E}$ & $\mathrm{o} / \mathrm{o}$ & $\mathrm{N} / \mathrm{E}$ \\
\hline \multirow[t]{2}{*}{ Nest position } & Elevated & $23 / 4$ & Neutral & $18 / 5$ & Neutral \\
\hline & Ground & $3 / 3$ & $\mathrm{~N} / \mathrm{E}$ & $5 / 2$ & Increase \\
\hline \multirow[t]{2}{*}{ Diet breadth } & Generalist & $15 / 3$ & Neutral & $12 / 3$ & Neutral \\
\hline & Specialist & $11 / 4$ & Neutral & $11 / 4$ & Neutral \\
\hline \multirow[t]{2}{*}{ Development } & Altricial & $25 / 6$ & Neutral & $18 / 5$ & Neutral \\
\hline & Precocial & $1 / 1$ & $\mathrm{~N} / \mathrm{E}$ & $5 / 2$ & Increase \\
\hline
\end{tabular}

a phylogenetic meta-analysis procedure for the whole species dataset, we did not find a significant effect of habitat fragmentation on brood size $(E=-201.7 ; \mathrm{SE}=623.0 ; t=-0.324 ; P=0.749$; $\left.P_{\text {rand }}=0.211\right)$ or on clutch size $\left(E=-161.2 ; \mathrm{SE}=781.7 ; t=-0.206 ; P=0.838 ; P_{\text {rand }}=0.407\right)$. Small sample sizes precluded performing further statistical analyses, considering that the 69 study cases gathered represented 15 species of 10 families (Table 1 ). Only one of the studied species, the Lesser Prairie-chicken Tympanuchus pallidicinctus, is of conservation concern (Vulnerable; BirdLife International 2008).

\section{Discussion}

The number of research papers on habitat fragmentation is increasing exponentially (Lampila et al. 2005), but research on variation with regard to reproductive life history traits is notably scarce despite its direct bearing on population management. Several articles dealt only with one fragment (e.g. Brown and Roth 2002, 2004), or did not compare reproductive life history traits with continuous habitat (e.g. Möller 1991), and only one dealt with a threatened species. Thus, apparently many studies on fragmentation lack adequate controls and research is ignoring endangered species.

On an overall analysis (considering all species and populations studied, with and without phylogenetic correction) the available evidence suggests that fragmentation has no effect on clutch and brood sizes, implying that no action would be required at this level for managing birds in fragmented forests. Nevertheless, we detected a significant heterogeneity indicating that the variance among effect sizes in the studied cases is greater than expected by chance. The consideration of underlying data structure in the meta-analysis (Rosenberg et al. 2000), based on secondary life history traits, has allowed us to test for underlying heterogeneity. Thus, although no significant effects were observed for clutch size due to other life history traits, when looking at brood size we detected that large bodied, ground nesting, and precocial species (e.g. Black Grouse Tetrao tetrix, Western Capercaillie T. urogallus, and Lesser Prairie-chicken) have larger brood sizes in forest fragments. Consequently, trait-dependent responses are likely in certain groups, which may be masked by the overall trend. We have performed phylogenetic meta-analysis by examining the variation in clutch and brood sizes in birds inhabiting fragmented and continuous habitats. Although this evidence seems to contradict the idea that large-bodied taxa might be more vulnerable to habitat fragmentation (Gaston and Blackburn 1995, Ewers and Didham 2006), published data (Lampila et al. 2005, Patten et al. 2005) suggest that adult survival in fragmented habitats decreases coupled with increased clutch or brood sizes, which might reflect a trade-off between reproductive effort and survival (Roff 1992, Stearns 1992). However, given that only three large species have been studied so far, whether the 
observed increased reproductive effort is a general phenomenon is yet to be confirmed. We know very little about the impacts of fragmentation on life histories but based on our evidence we cannot discard the possibility that certain groups (e.g. large-bodied precocial birds) might show a significant response in reproductive efforts.

Despite claims regarding the need for evidence-based conservation, and to incorporate microevolutionary aspects in the management of endangered biota (Stockwell et al. 2003, Sutherland et al. 2004), the scarcity of available information renders such an approach unfeasible when applied to birds occupying fragmented habitats. This finding is particularly distressing considering that bird diversity is negatively affected by habitat fragmentation, and they are common subjects in fragmentation studies (Clark and May 2002, Fazey et al. 2005). Clearly the call to generate and share relevant information (Milner-Gulland 2009) to support more robust meta-analysis that could be used to inform conservation actions, is supported by the lack of information about birds in fragmented habitats. In order to improve our understanding regarding if and how changes on reproductive life history traits impinge upon birds persistence we must focus habitat fragmentation research on behavioural ecology and life history trait variation of conservation-concern species.

\section{Acknowledgements}

We are grateful to R. O. Bustamante and A. Arredondo for insightful methodological discussions. We especially thank Dean C. Adams for providing assistance with the phylogenetic meta-analysis. RRV thanks a Russell E. Train Education for Nature Program/WWF fellowship (WWF-EFN $\mathrm{RP}_{42}$ ). RRV and FEF were supported by Doctoral Fellowships granted by the Chilean Commission of Scientific and Technological Research (CONICYT).

\section{References}

Adams, D. C. (2008) Phylogenetic meta.analysis. Evolution 62: 567-572.

Adams, D. C., Gurevitch, J. and Rosenberg, M. S. (1997) Resampling test for meta-analysis of ecological data. Ecology 78: 1277-1283.

Batary, P. and Baldi, A. (2004) Evidence of an edge effect on avian nest success. Conserv. Biol. 18: 389-400.

BirdLife International (2008) Tympanuchus pallidicinctus. In IUCN. 2010. IUCN Red List of threatened species. Version 2010.2. http://www.iucnredlist.org. Downloaded on 29 July 2010.

Brown, W. P. and Roth, R. R. (2002) Temporal patterns of fitness and survival in the wood thrush. Ecology 83: 958-969.

Brown, W. P. and Roth, R. R. (2004) Juvenile survival and recruitment of wood thrushes Hylocichla mustelina in a forest fragment. J. Avian Biol. 35: 316-326.

Clark, J. A. and May, R. M. (2002) Taxonomic bias in conservation research. Science 297: 191-192.

Ericson, P. G. P., Anderson, C. L., Britton, T., Elzanowski, A., Johansson, U. S., Källersjö,
M., Ohlson, J. I., Parsons, T. J., Zuccon, D. and Mayr, G. (2006) Diversification of Neoaves: integration of molecular sequence data and fossils. Biol. Lett. 2: 543-547.

Ewers, R. M. and Didham, R. K. (2006) Confounding factors in the detection of species responses to habitat fragmentation. Biol. Rev. Camb. Philos. Soc. 81: 117-142.

Fahrig, L. (2003) Effects of habitat fragmentation on biodiversity. Annu. Rev. Ecol. Syst. 34: 487-515.

Fazey, I., Fischer, J. and Lindenmayer, D. B. (2005) What do conservation biologists publish? Biol. Conserv. 124: 63-73.

Gaston, K. J. and Blackburn, T. M. (1995) Birds, body-size and the threat of extinction. Philos. Trans. R. Soc. Lond., Ser. B 347: 205-212.

Hackett, S. J., Kimball, R. T., Reddy, S., Bowie, R. C. K., Braun, E. L., Braun, M. J., Chojnowski, J. L., Cox, W. A., Han, K.-L., Harshman, J., Huddleston, C. J., Marks, B. D., Miglia, K. J., Moore, W. S., Sheldon, F. H., Steadman, D. W., Witt, C. C. and Yuri, T. (2008) A phylogenomic study of birds 
reveals their evolutionary history. Science 320: $1763-1768$.

Kawecki, T. J. and Ebert, D. (2004) Conceptual issues in local adaptation. Ecol. Lett. 7: 1225-1241.

Lampila, P., Monkkonen, M. and Desrochers, A. (2005) Demographic responses by birds to forest fragmentation. Conserv. Biol. 19: 1537-1546.

Lees, A. C. and Peres, C. A. (2008) Avian lifehistory determinants of local extinction risk in a hyper-fragmented neotropical forest landscape. Anim. Conserv. 11: 128-137.

Milner-Gulland, E. J., Fisher, M., Browne, S. Redford, K. H., Spencer, M., and Sutherland, W. J. (2009) Do we need to develop a more relevant conservation literature? Oryx 44: 1-2.

Möller, A. P. (1991) Clutch size, nest predation, and distribution of avian unequal competitors in a patchy environment. Ecology 72: 1336-1349.

Patten, M. A., Wolfe, D. H., Shochat, E. and Sherrod, S. K. (2005) Habitat fragmentation, rapid evolution and population persistence. Evol. Ecol. Res. 7: 235-249.

Piersma, T. and Drent, J. (2003) Phenotypic flexibility and the evolution of organismal design. Trends Ecol. Evol 18: 228-233.
R Development Core Team (2006) R: A language and environment for statistical computing. Vienna, Austria: R Foundation for Statistical Computing.

Ricklefs, R. E. (1991) Structures and transformations of life histories. Funct. Ecol. 5: 174-183.

Roff, D. (1992) Evolution of life histories: theory and analysis. New York: Chapman \& Hall.

Rosenberg, S. M., Adams, D. and Gurevitch, J. (200o) MetaWin: statistical software for meta-analysis version 2. Sunderland, MA: Sinauer Associates, Inc.

Stearns, S. C. (1992) The evolution of life histories, Oxford University Press, Oxford.

Stockwell, C. A., Hedry, A. P. and Kinnison, M. T. (2003) Contemporary evolution meets conservation biology. Trends Ecol. Evol 18: 94-101.

Sutherland, W. J., Pullin, A. S., Dolman, P. M. and Knight, T. M. (2004) The need for evidence-based conservation. Trends Ecol. Evol 19: 305-308.

Zwickl, D. J. (2006) Genetic algorithm approaches for the phylogenetic analysis of large biological sequence datasets under the maximum likelihood criterion. $\mathrm{PhD}$ dissertation, The University of Texas at Austin.

RENZO R. VARGAS*, FRANCISCO E. FONTÚRBEL, JAVIER A. SIMONETTI

Departamento de Ciencias Ecológicas, Facultad de Ciencias, Universidad de Chile, Casilla 653, Santiago, Chile.

\section{ELISA BONACORSO}

Centro de Investigación en Biodiversidad y Cambio Climático, Universidad Tecnológica Indoamérica, Machala y Sabanilla, Quito, Ecuador.

*Author for correspondence; email: renzo_vr@gmx.net

Received 27 August 2010; revision accepted 15 September 2011; Published online 16 December 2011 